\title{
Dientamoeba fragilis detection in suid populations: an emerging zoonosis hypothesized in Central Italy
}

\author{
Daniele Crotti ${ }^{3}$, Silvia Crotti', Marco Sensi', Sonia Salamida', Elisabetta Manuali', \\ Simone M. Cacciòn', Edoardo Pozio² \\ I Istituto Zooprofilattico Sperimentale dell'Umbria e delle Marche, Perugia; \\ 2 Istituto Superiore di Sanità, Rome; \\ 3 DHM, Independent Consultant
}

Key words: Dientamoeba fragilis, Epidemiology, Giemsa stain, Molecular biology, Swine, Zoonoses

Reperimento di Dientamoeba fragilis in popolazioni di suidi: una ipotizzata zoonosi emergente

\section{SUMMARY}

Dientamoeba fragilis ( $D$. fragilis) is a worldwide distributed protozoan parasite; it is pathogenic for humans.A wide spectrum of gastrointestinal symptoms has been described in infected patients: diarrhoea, flatulence, abdominal pains, colic and weight loss. However, asymptomatic infection has been also described. $D$. fragilis is still not well known; no cystic stage has been demonstrated and only the trophozoites are detected in stool samples.

For identifying this typically more often binucleate protozoan, is necessary to perform permanent stain (eg. Giemsa) on fresh stool specimens. This protozoan is extremely difficult to cultivate but molecular techniques such as the Polymerase Chain Reaction offer promise as a means of diagnosing infection.

In five years time (2006-20I0), faecal samples were collected from pigs housed in farrow-to-finish herds (494 samples, splitted in three different categories: sows, growers, finishing pigs) and from hunted or slaughtered wild boars (87 samples). Simultaneously, the study was undertaken on human faeces (17 samples) to evaluate the presence of $D$. fragilis in pig breeders. All samples were collected directly from the rectum, cooled and sent to the laboratory where they were examined for $D$. fragilis by direct microscopic examination.

The fresh faecal smears were stained with a 10\% Giemsa solution in distilled water for 30 min.

Biomolecular investigations (TaqMan real-time PCR which targets the 5.8S rRNA, nested PCR for the I8S rRNA, nested PCR for the internal transcribed spacer I region) were carried out on 38 pigs and 17 pig breeders specimens. The microscopic examination of the fresh fecal smears revealed positivity in 277 domestic pigs, corresponding to $56.07 \%$. In particular higher positivity was observed on youngest animal $(76.57 \%)$, while oldest or mature pigs recorded an important decreasing of positivity according the age (Table I). Concerning wild boars, we revealed positivity in 35 animals (40.22\%). Among humans, the positivity was $76.47 \%$ and these positive specimens came from people with a close contact with pigs. Biomolecular investigations carried out on human and animals amplified positive products revealed 100\% homology with the 5.8S rRNA gene of D. fragilis, genotype I (e.g., Genbank DQ23345I). During a five years research project we demonstrated the presence of $D$. fragilis in domestic pigs populations as well as in hunted or slaughtered wild boars. Due to the high percentage of positivity we could assume the domestic and/or wild pigs can play a role as natural reservoir of the parasite.

In this scenario, outdoor pig farms and/or "confined" wild boars rearing can act as important link of exchange of this parasite. The demonstrated homology of $D$. fragilis sequences obtained from both humans and animals suggests the potential role of this parasite as zoonotic agent. If an environmentally resistant and infective stage of $D$. fragilis exists, we suppose the environmental contamination with domestic/wild pigs feces could be as an important factor in the transmission of this parasite to other hosts, including humans.

\section{INTRODUCTION}

Dientamoeba fragilis (D. fragilis) is a worldwide distributed protozoan parasite. The infection is highly prevalent in both economically developing regions and industrialized countries of the world $(2-4,14,18,23)$.

It is pathogenic for humans and it is one of the most common parasites of the intestinal tract of humans. A wide spectrum of gastrointestinal symptoms has been described in infected patients: diarrhoea (rarely severe), flatulence, abdominal pains, colic and weight loss. However, asymptomatic infection has been also described. Moreover an increase on blood eosinophilia is not rare (3$10,21,23,25,26,28)$.

D. fragilis is still not well known; no cystic stage has been demonstrated and only the trophozoytes are detected in stool samples $(7,18)$. Particularly,

Corresponding author: Daniele Crotti

Strada Comunale per Pilonico Paterno 4

06 I 34 Perugia, Italy - Tel.: 0039075602372

E-mail:daniele.nene@email.it 
very little is known about transmission routes and the natural host range of this parasite $(15,18)$. Other than humans, very few animal hosts have been reported. Surveys of mammals and birds have identified only non-human primates (gorilla, macaque and baboon) as natural hosts $(19,27)$. Recently, however, a high prevalence of infection $(43.8 \%)$ has been reported in breeding and fattening pigs in Italy using microscopy (11-13).

If the prevalence, in the epidemiology, could be related to life and sanitation standard of the examined populations, the diagnostic methodologies are related to specimens' numbers for each subject, to use o permanent stain, to specific cultures, to experience and capability of parasitologyst (3, $5,14,16,18,21,26)$.

In this scenario the molecular techniques could help in the diagnosis or could be important for understanding more peculiarities regarding epidemiology, transmission and reservoir of this suggestive protozoon $(22,24,29)$.

D. fragilis belongs to Philum Sarcomastigophora, Class Zoomastigophora, Order Trichomonadida, Family Monocerca monadidae.

D. fragilis is a flagellate like Giardia duodenalis (G. duodenalis), but it is "ameba - like"; usually there are 2 nuclei (rarely, in humans, only one and exceptionally four), and it is considered "fragile" because scantly resistance out of bowels (18).

For identifying this atypical flagellate protozoon, it is necessary to perform permanent stain (eg. Giemsa: the best one in our experience) on fresh stool specimens. This protozoon is difficult to cultivate but molecular techniques such as the Polymerase Chain Reaction offer promise as a means of diagnosing infections $(3,4,24)$.

In this work we report our experience concerning the prevalence of $D$. fragilis in humans during last ten years, the presence of this protozoon in domestic pigs and wild boars faeces, the evaluation of the possible role of these animals as reservoir of the parasite, particularly in relation to specific molecular techniques adopted for characterizing the parasite protozoa from faecal samples collected from pigs and pigs farmers $(1,11-13)$.

\section{MATERIALS AND METHODS}

Between 2002 and 2004 we investigated for research of $D$. fragilis the stool specimens of 380 children and 656 adult suffering from intestinal troubles or colitis, 546 children and 291 adults with severe diarrhoea, 40 children and 76 adult with protracted diarrhoea, in Perugia, Italy $(4,6,7)$.

During 2006 we investigated the stool specimens of 81 extra-community immigrants adult population in Naples, Italy, for research parasites including D. fragilis (20). During 2007 we analyzed the faeces of 91 subjects, 38 children and 53 adults, in a Peruvian zone, for a preliminary survey of human intestinal parasitosis in indigenous people (2).

In five years time, between 2006 and 2010, faecal samples were collected from pigs housed in farrow-to-finish herds (11-13); they were 494 samples splitted in three different categories: sows (166 samples), growers (22 samples), finishing pigs (106 samples). Again, we collected, always for research of $D$. fragilis, the stools of 87 hunted or slaughtered wild boars.

Moreover, 17 stool specimens of pigs breeders were analyzed for evaluating the presence of $D$. fragilis.

Over all specimens belonged to subjects or animals in the Umbria region of middle Italy.

All faecal specimens of suids were collected directly from rectum, cooled and sent to the laboratory for research of $D$. fragilis.

All faecal human and animal specimens were collected without preservative, sent to microbiological laboratory and analyzed for the presence of $D$. fragilis at optical microscopy. All the fresh faecal smears were fixed with methanol for $1-2$ minutes, and after stained with a $10 \%$ Giemsa solution in distilled water for 30 minutes. The microscopic observations at $100 \mathrm{x}$ with Giemsa stain for D. fragilis highlights these features: shape is variable, rounded or elongated ("amoeba-like"); cytoplasm is gray - azure - blue with granulations, inclusions, vacuoles; nuclei, 1 or 2 (very rarely 4) are red - violet and fragmented (anyway never compact); no peripherical chromatin is present. In other words, microscopic diagnosis of $D$. fragilis was based on visualization of pleomorphic trophozoites, ranging in size from 4 to 30 or more $\mu \mathrm{m}$, with fragmented chromatin and pale grey blue finely vacuolated cytoplasm $(3-6,9)$.

During June-August 2010, a total of 152 faecal samples were collected from the rectum of piglets (age: 1-3 months, weight: $6-25 \mathrm{~kg}$ ), fattening pigs (3-4 months, 25-50 kg) and sows (1-2 years, 180$250 \mathrm{~kg}$ ) raised in 6 farrow-to-finish, 2 flattening and 1 weaner indoor farms of central Italy ( 7 in the Umbria region and 2 in near Marche region). Pig samples from 7 of the 9 farms were available for molecular analysis. 21 faecal samples from pig farmers were collected in 5 of the 9 farms, but only 17 samples were available for molecular analysis. The microscopic diagnosis of $D$. fragilis was performed as before explaned.

DNA was extracted directly from faecal material using a commercial kit. A TaqMan real-time PCR assay was used as a diagnostic tool. Next, a fragment of the 18S rRNA gene, as well as the internal transcribed spacer 1 (ITS 1) region, were amplified by PCR and sequenced. The sequences were assembled using Seqman II, and compared 
with those available in public databases using BLAST (1).

\section{RESULTS}

During first decade of XXI century D. fragilis was often observed in humans specimens as in bibliography reported $(3-10,14)$.

In this paper we report only the data of three years, particularly between 2002 and 2004, moreover already published. $D$. fragilis was the prevalent protozoon and the prevalent parasite observed in humans. Among adults with not specific intestinal bowel disease, or asymptomatic subjects, $D$. fragilis was identified in 57 cases (8.7\%); among adults with sever diarrhoea $D$. fragilis was observed in 13 cases (4.5\%); among adults with protracted diarrhoea $D$. fragilis was reported in 5 cases $(6.6 \%)$. Regarding children $(1-14$ years old), these were the results: 2 case $(0.5 \%), 2$ cases $(0.2 \%)$, and 1 case $(2.5 \%)$ respectively. All data are reported in Table 1. D. fragilis was always more frequent than $G$. duodenalis or other protozoa, pathogens or not, Blstocystis hominis included, as the same Table 1 shows $(7,8)$.

As Table 2 shows, among extra-community immigrants, in Naples, during 2006, D. fragilis was yet the more prevalent parasite in stool specimens observed of these subject: 19 cases, $23.5 \%$ (20).

In Table 3 we report our data regarding a preliminary survey of human intestinal parasitosis in a Peruvian Andean zone, and, again, D. fragilis was the most frequent protozoon and the most frequent parasite: it was observed in 28 cases $(30.8 \%)$, and specifically in 17 cases $(32.1 \%)$ among adults and in 11 cases (28.9\%) among children (2).

The microscopic examination of the fresh faecal smears among domestic pigs revealed positivity for $D$. fragilis in 277 domestic pigs, corresponding to $56.1 \%$ (Table 4 ). In particular higher positivity for this protozoon was observed on youngest animal: 170 cases, $76.6 \%$, while oldest or mature pigs recorded an important decreasing of positivity according the age; so, among finishing pigs $D$. fragilis was observed in 62 cases $(58.5 \%)$, and among sows in 45 cases, $27.1 \%$. All is presented in Table 4. Concerning wild boars, we revealed positivity for $D$. fragilis in 35 cases $(40.2 \%)$.

Among humans (pig breeders), we analyzed only 17 stool specimens, but the positivity for $D$. fragilis was surely high: 13 cases (76.5\%), as reported in the same Table 4.

In Figure I we present an image of $D$. fragilis observed in human stools; in Figure II an image of stool pig's $D$. fragilis is presented; in Figure III we present an image of $D$. fragilis from a wild boar stool specimen. In all these three images $D$. fragilis present a double nucleus, and all three ones are typical coloured. In Figure IV we report a trophozoyte of $D$. fragilis presenting 4 nuclei. Now we report the results relating to the 152 faecal samples collected from pigs between June and August of 2010: morphological and bio-molecular examinations. The microscopic examination revealed that 52 of the 74 piglets, 11 of the 14 fattening pigs, and 8 of the 64 sows were positive for D. fragilis, whereas of the 21 samples from pig framers, 4 from farmers working on two farms, were positive. Molecular techniques were applied to 38 pig faecal samples, namely 24 microscopically positive samples from 6 farms and 14 microscopically negative samples from 2 farms, and to 17 human faecal samples from 5 farms of which 4 were microscopically positive for this atypical flagellate protozoon. Using a TaqMan real-time PCR assay that targets the 5.8S rRNA gene, all 24 microscopically positive pig samples were amplified, with $\mathrm{Ct}$ values ranging from 30 to 34 , whereas none of the microscopically negative samples were positive to this assay. Of the 17 human faecal samples, 13 were positive with $\mathrm{Ct}$ values ranging from 29 to 40. The sequence analysis of the 5.8S rRNA gene from 15 amplified products (11 from pigs and 4 from humans) revealed $100 \%$ homology with $D$. fragilis genotype 1 . Genotype 2 was not found in any of the samples from pigs or humans. Amplification and sequencing of a $366 \mathrm{bp}$ fragment of the 18S rRNA gene confirmed the presence of genotype 1 in 6 pig samples and I 8 human samples, and indicate a very limited genetic polymorphism in this gene. Finally, the analysis of the more variable ITS1 region indicate that the genotypes found in 2 pig samples are identical to genotypes previously found in humans. A direct comparison of parasite isolates from pigs and pig farmers from the same farm was, unfortunately, not possible.

\section{CONCLUSIONS AND DISCUSSION}

We want to focus the results of morphological and bio-molecular examinations of the last 10 years, and particularly of the last 5 years, between 2006 and 2010.

During this last five years research project we demonstrated the presence of $D$. fragilis in domestic pigs populations as well as in hunted or slaughtered wild boars. Particularly, the microscopic examination of the faecal smears revealed positivity in 277 domestic pigs, corresponding to $58.1 \%$; higher positivity was observed on youngest animals $(76.6 \%)$, while oldest or mature pigs recorded an important decreasing of positivity according the age. Concerning wild boars, we revealed positivity in 35 animals, corresponding to $40.2 \%$.

Among humans the positivity was $76.5 \%$ and these positive specimens came from people with a 
close contact with pigs.

Due to the high percentage of positivity we could assume the domestic and/or wild pigs can play a role as natural reservoir of $D$. fragilis. In this scenario, outdoor pigs farms and/or "confined" wild boars rearing can act as important link of exchange of this parasite.

Considering the size of the world's pig population (more than 1 billion), the close contact between pigs and humans in many parts of the world, and the difficulties in the proper management of pig faecal waste, the role of these animals as reservoirs of zoonotic pathogens must be carefully evaluated. Here, we demonstrated that pigs are host of $D$. fragilis based on molecular analysis of three fragments in the ribosomal cluster. Sequencing of fragments of the $18 \mathrm{~S}$ and $5.8 \mathrm{~S}$
DNA revealed genotype 1 in both human and pig isolates collected in the same farm, suggesting the potential for zoonotic transmission of this parasite. Characterization of the more polymorphic ITS1 locus also revealed that pigs harbour genotypes previously found in humans, but the specificity of this assay is limited, particularly when other flagellates are present in stools.

If a transmittable cyst stage, or better an environmental resistant and infective stage, of $D$. fragilis exists, then environmental contamination with pig faeces should considered as an important factor in the transmission of this parasite.

This study was supported by a research grant from the Italian Ministry of Health (IZSUM 16/09 RC) and by the European Commission (contract SANCO/20006/FOODSAFETY/32).

Table I. Hospitalized people with enteric problems, Perugia, Italy, between 2002 and 2004: result regarding parasites investigations.

\begin{tabular}{|c|c|c|c|c|c|c|}
\hline & \multicolumn{2}{|c|}{ Not specific bowel disease } & \multicolumn{2}{|c|}{$\underline{\text { Severe diarrhoea }}$} & \multicolumn{2}{|c|}{ Protracted diarrhoea } \\
\hline & $\begin{array}{c}\text { Children } \\
N^{\circ} 380\end{array}$ & $\begin{array}{r}\text { Adults } \\
\mathrm{N}^{\circ} 656\end{array}$ & $\begin{array}{c}\text { Children } \\
N^{\circ} 546\end{array}$ & $\begin{array}{l}\text { Adults } \\
N^{\circ} 291\end{array}$ & $\begin{array}{c}\text { Children } \\
\mathrm{N}^{\circ} 40\end{array}$ & $\begin{array}{l}\text { Adults } \\
\mathrm{N}^{\circ} 76\end{array}$ \\
\hline D. fragilis & $2(0.5 \%)$ & $57(8.7 \%)$ & $2(0.4 \%)$ & $13(4.5 \%)$ & $2(5.0 \%)$ & $5(6.6 \%)$ \\
\hline G. duodenalis & $2(0.5 \%)$ & $24(5.7 \%)$ & 0 & $5(1.7 \%)$ & 0 & $4(5.3 \%)$ \\
\hline B. hominis & $2(0.5 \%)$ & $24(5.7 \%)$ & I (0.2\%) & I (0.3\%) & I (2.5\%) & $4(5.3 \%)$ \\
\hline Not pathogenic & & & & & & \\
\hline Protozoa & 0 & II (I.7\%) & 0 & 0 & 0 & 0 \\
\hline Helminths & 0 & $5(0.8 \%)$ & 0 & 0 & 0 & 0 \\
\hline
\end{tabular}

Table 2. Results of parasitological investigations among an extra-community immigrants population (8I subjects), Naples, 2006.

\begin{tabular}{|l|c|c|}
\hline \multicolumn{1}{|c|}{ PARASITE } & NUMBER OF CASES & PERCENTAGE \\
\hline Dientamoeba fragilis & 9 & $23.5 \%$ \\
Hookworms & 17 & $21.1 \%$ \\
Trichuris trichiura & 3 & $3.7 \%$ \\
Entamoeba histolyticaldispar & 2 & $2.5 \%$ \\
Giardia duodenalis & 1 & $1.2 \%$ \\
Schistosoma mansoni & 1 & $1.2 \%$ \\
Ascaris lumbricoides & 1 & $1.2 \%$ \\
\hline
\end{tabular}

Table 3. Results of a preliminary survey concerning human intestinal parasitosis in Perù, 2007.

\begin{tabular}{|l|c|c|c|c|c|c|}
\hline \multicolumn{1}{|c|}{ PARASITE } & \multicolumn{2}{c|}{$\begin{array}{c}\text { CHILDREN } \\
\text { (38 subjects) }\end{array}$} & \multicolumn{2}{c|}{$\begin{array}{c}\text { ADULTS } \\
\text { (53 subjects) }\end{array}$} & \multicolumn{2}{c|}{$\begin{array}{c}\text { TOTAL } \\
\text { (91 subjects) }\end{array}$} \\
\hline Dientamoeba fragilis & 11 & $28.9 \%$ & 17 & $32.1 \%$ & 28 & $30.8 \%$ \\
Giardia duodenalis & 8 & $21.1 \%$ & 3 & $5.7 \%$ & 11 & $12.1 \%$ \\
Balantidium coli & 0 & - & 1 & $1.9 \%$ & 1 & $1.1 \%$ \\
\hline TOTAL pathogen protozoa & 19 & $50.0 \%$ & 21 & $39.6 \%$ & 40 & $44.0 \%$ \\
\hline Ascaris lumbricoides/spp. & 7 & $18.4 \%$ & 7 & $13.2 \%$ & 14 & $15.4 \%$ \\
Trichuris trichiura & 1 & $2.6 \%$ & 1 & $1.9 \%$ & 2 & $2.2 \%$ \\
Enterobius vermicularis & 1 & $2.6 \%$ & 0 & - & 1 & $1.1 \%$ \\
Fasciola hepatica & 0 & - & 1 & $1.9 \%$ & 1 & $1.1 \%$ \\
Hymenolepis nana & 2 & $5.3 \%$ & 1 & $1.9 \%$ & 3 & $1.1 \%$ \\
\hline TOTAL helminths & 11 & $28.9 \%$ & 10 & $18.9 \%$ & 21 & $23.1 \%$ \\
\hline Not pathogen protozoa & 5 & $13.2 \%$ & 10 & $18.9 \%$ & 15 & $16.5 \%$ \\
\hline Negative samples & 13 & $34.2 \%$ & 17 & $32.1 \%$ & 30 & $33.0 \%$ \\
\hline
\end{tabular}


Table 4. Results of D. fragilis examinations from pigs, wild boars and humans (with a close contact with pigs) specimens, 2006 - 2010.

\begin{tabular}{|c|c|c|c|}
\hline ANIMALS & $\begin{array}{c}\text { Samples' } \\
\text { number }\end{array}$ & $\begin{array}{c}\text { Positive's } \\
\text { number }\end{array}$ & $\begin{array}{c}\text { Positives' } \\
\text { percentage }\end{array}$ \\
\hline Sows & 166 & 45 & $27.1 \%$ \\
Growers & 222 & 170 & $76.6 \%$ \\
Finishing - pigs & 106 & 62 & $58.5 \%$ \\
Wild boar & 87 & 35 & $40.2 \%$ \\
\hline HUMANS & 17 & 13 & $76.5 \%$ \\
\hline
\end{tabular}

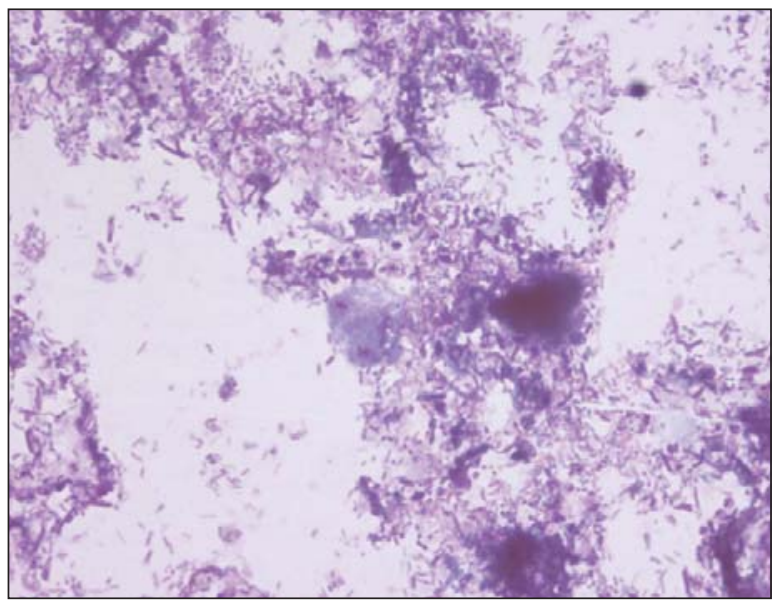

Figure I. D. fragilis from human faeces.

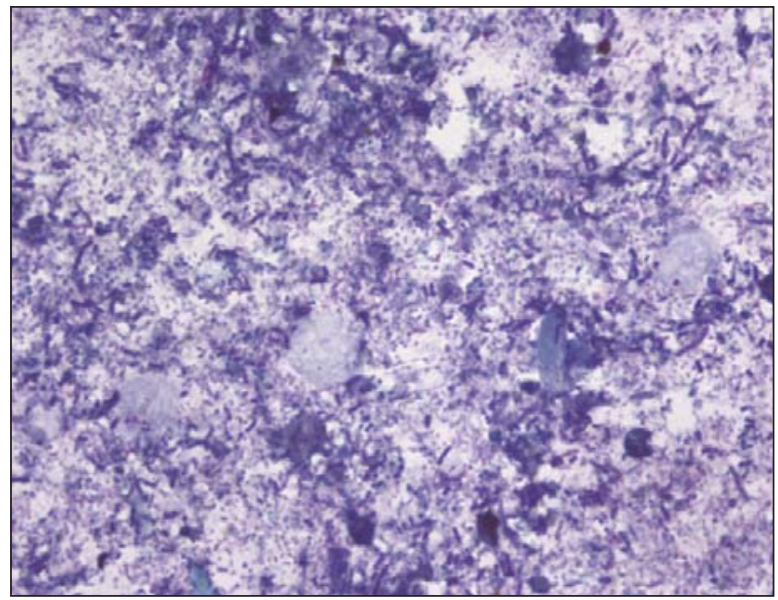

Figure III. D. fragilis in wild boars faeces.

\section{REFERENCES}

1. Cacciò SM, Sannella AR, Manuali E, et al. Pigs as Natural Hosts of Dientamoeba fragilis Genotypes Found in Humans. EID 2012; 18 (5): 838-41.

2. Crotti D. Diario peruano 2006, in: Cristallo AF, La Medicina di Laboratorio nella Pratica Medica, Volume 2, Selecta Medica, Pavia, 2007.

3. Crotti D, D'Annibale ML. Dientamoeba fragilis e dientamoebosi: aspetti di parassitologia clinica e diagnostica di Laboratorio. Parassitologia 2001; 43: 135-8.

4. Crotti D, D'Annibale ML. Dientamoeba fragilis: suo ruolo nelle infezioni intestinali umane. Infez Med 2007; $1: 30-9$

5. Crotti D, D'Annibale ML. Attualità in tema di infezioni intestinali causate da Dientamoeba fragilis e

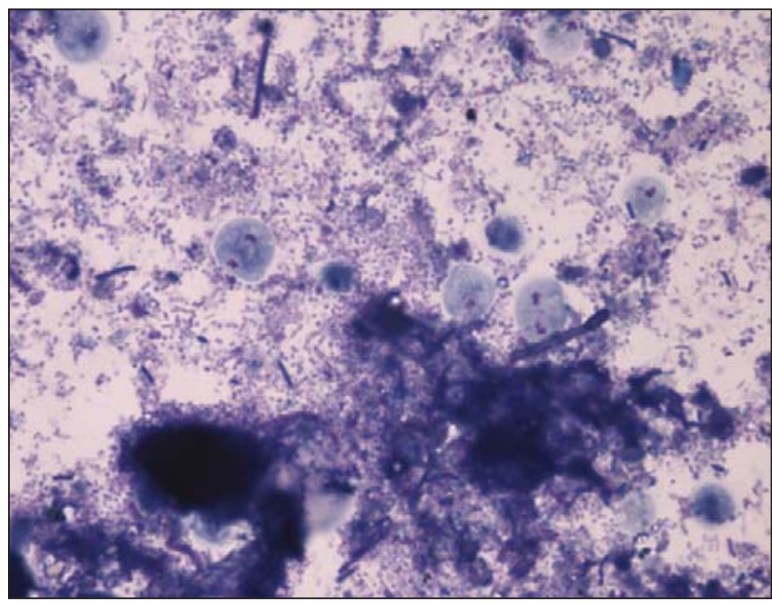

Figure II. D. fragilis in pig's stool specimen.

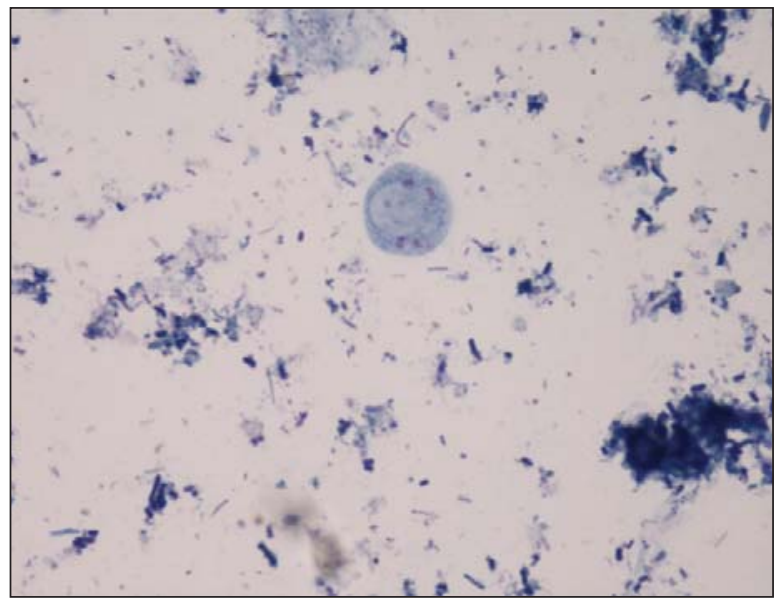

Figure IV. D. fragilis with 4 nuclei.

Giardia duodenalis. Recenti Progressi in Medicina 2007; 98 (6): 361-6.

6. Crotti D, D'Annibale ML. Enteriti acute e protratte nell'uomo: prevalenze eziologiche ed aspetti di metodologia diagnostica. Microbiol Med 2007; 22 (1): 20-5.

7. Crotti D, D'Annibale ML. Parassitosi intestinali autoctone: ruolo di Dientamoeba fragilis nelle infezioni umane. Ann Ig 2007; 19: 27-34.

8. Crotti D, D'Annibale ML, Fonzo G, Lalle M, Cacciò SM, Pozio E. Dientamoeba fragilis is more prevalent than Giardia duodenalis in children and adults attending a day care centre in Central Italy. Parasite 2005; 12: $165-70$.

9. Crotti D, D’Annibale ML, Fonzo G, Medori MC, Ubaldi M. Diarree acute e protratte nella popolazione del territorio perugino: diagnosi microbiologica delle 
enteriti ed aspetti clincio-epidemiologici relativi al 2001. Infez Med 2002; 2: 81-7.

10. Crotti D, D’Annibale ML, Medori MC, Fonzo G, Ubaldi M. Parassitosi intestinali autoctone nell'area del Perugino: considerazioni di metodologia diagnostica e prevalenze nel corso del 2001. GIMMOC Vol. VII No ${ }^{\circ}$ : 12-20.

11. Crotti D, Sensi M, Crotti S, Grelloni V, Manuali E. Dientamoeba fragilis in swine population: A preliminary Investigation. Veterinary Parasitology 2007; 145: 349-51.

12. Crotti D, Sensi M, Manuali E, Crotti S. Dientamoeba fragilis nella popolazione suina: indagini preliminari. Microbiol Med 2007; 22 (4): 321-3.

13. Crotti D, Sensi M, Salamida S, Crotti S, Manuali E. Could be the swine responsible of transmission to the Humans of Dientamoeba fragilis infection? Microbiol Med 2011; 26 (1): 51-7.

14. D’Annibale ML, Bracciale S, Vitali M, Fonzo G, Verdini C, Papili R. Parasitic intestinal infections in humans Between 2006 and 2007. Microbiol Med 2009; 24 (1): 19-24.

15. D’Annibale ML, Crotti D. Parassitosi intestinali umane nel Perugino nel corso del 2005. Microbiol Med 2007; 22 (1): 57-65.

16. Guidetti C, Ricci L, Vecchia L. Intestinal parasitosis in a population of foreign subjects of recent immigration. Microbiol Med 2011; 26 (1): 60-6.

17. Johnson Ja, Clark CG. Cryptic Genetic Diversity in Dientamoeba fragilis. JCM 2000; 38 (1): 4653-4.

18. Johnson EH, Windsor JJ, Clark CG. Emerging from Obscurity: Biological, Clinical, and Diagnostic Aspects of Dientamoeba fragilis. CMR 2004; 17 (3): 553-70.

19. Lankester F, Kiyang JA, Bailey W, Unwin S. Dientamoeba fragilis: initial evidence of pathogenicity in the Western Lowland Gorilla (Gorilla Gorilla Gorilla). Journal of Zoo and Wildlife Medicine 2010; 41 (2): 350-2.

20. Nocera E, Bozzelli L, Gallo MA, et al. Epidemiologia delle parassitosi intestinali in una popolazione di immigrati extracomunitari. Microbiol Med 2006; 21 (4): 328-32.

21. Norberg A, Nord CE, Evengård B. Dientamoeba fragilis - a protozoal infection which may cause severe bowel Distress. Clinical Microbiology and Infection 2003; 9 (1): 65-8.

22. Peek R, Reedeker FR, van Gool T. Direct Amplification and Genotyping of Dientamoeba fragilis from Human Stool Specimens. JCM 2004; 42 (2): 631-5.

23. Stark D, Barrat J, Roberts T, Marriott D, Harkness J, Ellis J. A Review of the Clinical Presentation of Dientamoebiasis. Am J Trop Med Hyg 2010; 82 (4): 614-9.

24. Stark D, Beebe N, Marriott D, Ellis J, Harkness J. Detection of Dientamoeba fragilis in fresh stool specimens Using PCR. International Journal for Parasitology 2005; L 35: 57-62.

25. Stark D, Beebe N, Marriott D, Ellis J, Harkness J. Dientamoebiasis: clinical importance and recent advances. TRENDS in Parasitology 2006; 22 (2): 92-6.

26. Stark D, van Hal S, Marriott D, Ellis J, Harkness J. Irritable bowel syndrome: A review on the role of intestinal Protozoa and the importance of their detection and diagnosis. International Journal for Parasitology 2007; 37: 11-20.

27. Stark D, Phillips O, Peckett D, et al. Gorillas are a host for Dientamnoeba fragilis: An update on the life cycle and host distribution. Veterinary Parasitology 2008; 151: 21-6.

28. Vandenberg O, POeek R, Souayah H, et al. Clinical and microbiological features of dientamoebiasis in patients suspected of suffering from a parasitic gastrointestinal illness: A comparison of Dientamoeba fragilis and Giardia lamblia infections. Intern J Infect Dis 2006; 10: 255-61.

29. Windosr JJ, Clark CG, Macfarlane L. Molecular typing of Dientamoeba fragilis. Br J Biomed Sci 2004; 61 (3): 153-5. 